\title{
Desidratação osmótica de frutos de duas cultivares de abacaxi em xarope de açúcar invertido ${ }^{1}$
}

\author{
Rafael G. Dionello², Pedro A. Berbert ${ }^{3}$, Marília A. B. Molina ${ }^{4}$, Rozimar C. Pereira ${ }^{5}$, Alexandre P. Viana ${ }^{6} \&$ Vinicius O. Carlesso $^{3}$
}

\begin{abstract}
RESUMO
Propôs-se, neste trabalho, avaliar a cinética da desidratação osmótica de fatias de frutos de duas cultivares de abacaxi, Pérola e Smooth Cayenne, em xarope de açúcar líquido invertido sem diluição. Empregaram-se dois níveis de temperatura da solução de desidratação, 40 e $50{ }^{\circ} \mathrm{C}$, dois níveis de agitação, zero e $60 \mathrm{~min}^{-1}$, tempo de imersão de $2 \mathrm{~h}$ e a relação fruta:xarope de 1:10. Verificou-se que a relação fruta:xarope usada, foi suficiente para manter inalterada a concentração da solução osmótica ao longo da desidratação. Houve aumento de cerca de três vezes no teor de sólidos solúveis totais das fatias de abacaxi, não se observando diferenças em função da cultivar e da temperatura de desidratação; observou-se, também, que a redução de massa, a perda de água e o ganho de sólidos, foram maiores para amostras da cultivar Pérola que para aquelas da cultivar Smooth Cayenne.
\end{abstract}

Palavras-chave: Ananas comosus, Pérola, Smooth Cayenne, desidratação por imersão-impregnação, pré-processamento de frutas

\section{Osmotic dehydration of sliced pineapple of two cultivars in inverted sugar syrup}

\begin{abstract}
The objective of the present study was to investigate the kinetics of the osmotic dehydration of sliced pineapple of two cultivars, Pérola and Smooth Cayenne, in undiluted inverted sugar syrup. Osmotic dehydration was carried out using a fruit to syrup weight ratio of 1:10, and employing two levels of temperature of the solutions $\left(40\right.$ and $\left.50^{\circ} \mathrm{C}\right)$, two levels of agitation (zero and $60 \mathrm{~min}^{-1}$ ) for a total immersion time of $2 \mathrm{~h}$. Results showed that the fruit to syrup ratio employed did not alter the total soluble solids content of the osmotic solution at the end of the dehydration process. A threefold increase in the total soluble solids content in pineapple slices was observed after dehydration, irrespective of cultivar and temperature of the solution. Highest values of mass reduction, water loss and solids gain were observed for fruit slices of cultivar Pérola.
\end{abstract}

Key words: Ananas comosus, Pérola, Smooth Cayenne, dewatering impregnation soaking, preprocessing of fruit

\footnotetext{
1 Parte da Tese de Doutorado do primeiro autor, apresentada à UENF

2 Departamento de Fitossanidade/UFRGS. Avenida Bento Gonçalves 7712, CEP 91540-000, Porto Alegre, RS. E-mail: rafdionello@hotmail.com

3 LEAG/UENF. Av. Alberto Lamego 2000, CEP 28013-602, Campos dos Goytacazes, RJ. Fone: (22) 2739-7239. E-mail: pberbert@uenf.br; carlesso@uenf.br

${ }^{4}$ LBT/UENF. Fone: (22) 2739-7088. E-mail: mberbert@uenf.br

5 UFRB, Cruz das Almas, BA. Fone: (75) 3621-1220. E-mail: rozimarcp@uol.com.br

${ }^{6}$ LMGV/UENF. Fone: (22) 2739-7100. E-mail: pirapora@uenf.br
} 


\section{INTRODUÇÃO}

Um dos temas mais estudados atualmente no âmbito do pré-processamento de frutas tem sido a desidratação por imersão-impregnação, técnica mais comumente conhecida como desidratação osmótica. O método consiste na remoção parcial da água das frutas por meio da sua imersão, em forma integral ou em fatias, em soluções hipertônicas de um ou mais solutos. Em geral, a desidratação osmótica é utilizada como pré-tratamento na secagem por convecção de frutas, podendo remover até 50\% da água nelas contida, e conferindo ao produto melhor qualidade final, em termos de aroma, sabor, aparência e textura. A imersão das frutas em soluções concentradas de determinados tipos de açúcar, origina dois fluxos de massa opostos, pois as frutas contêm açúcares e outros solutos em solução diluída e sua estrutura celular superficial não pode ser considerada uma membrana perfeitamente semipermeável; em sendo assim, há uma saída de água da fruta para a solução e uma migração de solutos da solução para o sólido (Torreggiani \& Bertolo, 2001; Queiroz et al., 2007).

Diversos autores tem avaliado o potencial osmótico de vários tipos de soluto na desidratação osmótica de frutas, em substituição ao emprego de soluções concentradas de sacarose, principalmente para obtenção de alimentos funcionais, com a impregnação do soluto desejado ou para melhorar a qualidade final do produto nas etapas posteriores do processamento, por meio da retenção de pigmentos, compostos voláteis e ácido ascórbico. Entre os solutos pesquisados se encontram a cerelose (Martínez et al., 2007), maltose (Ferrari et al., 2005), maltodextrina (Azuara et al., 2002), manitol (Rodrigues \& Fernandes, 2007), sorbitol (Rizzolo et al., 2007) e trealose (Ferrando \& Spiess, 2001). Em contrapartida e apesar de todas as vantagens relacionadas à sua utilização, são também relativamente poucos os estudos da desidratação osmótica de frutas empregando-se o açúcar líquido invertido como agente osmótico (Queiroz et al., 2007; Dionello et al. 2007).

O açúcar líquido invertido é um produto amplamente utilizado na fabricação de alimentos, em especial nas indústrias de panificação, laticínios, refrigerantes, sucos, biscoitos e recheios, doces em compotas, frutas cristalizadas, balas, geléias, temperos e condimentos (DULCINI, 2000); trata-se de produto obtido pela hidrólise de soluções de sacarose, realizada tanto por via enzimática, em reação catalisada por invertase, quanto por via química, através do emprego de soluções ácidas. O grau de inversão das soluções, que representa a intensidade de quebra das moléculas presentes em seus dois monossacarídeos constitutivos, glicose e frutose, varia de 10 a 100\% (Queiroz, 2006). O xarope de açúcar invertido reúne a elevada solubilidade da frutose à difícil cristalização da glicose, aumentando seu poder edulcorante e diminuindo os riscos de cristalização, o que poderia conferir, ao produto, uma desagradável consistência arenosa (Rodrigues et al., 2000). Porém, um de seus principais benefícios consiste na maior capacidade de redução da atividade de água do alimento, fator determinante para ampliar seu prazo de validade (Hansson et al., 2001). Além disso, é importante ressaltar que o manuseio de ingredientes no estado líquido no processamento industrial de alimentos, é mais eficiente que no estado sólido.

No Brasil, país de origem e um dos principais produtores mundiais de abacaxi, há predominância no cultivo da cultivar Pérola, apesar da importância da cultivar Smooth Cayenne, sobretudo em algumas regiões produtoras no estado de São Paulo. O principal destino desses frutos tem sido o mercado nacional de frutas frescas e, em menor proporção, indústrias de suco, polpa, compotas e outras formas de processamento. Os estados de Minas Gerais e Paraíba são os maiores produtores de abacaxi no País, cujas produções, somadas, representam mais da metade da produção brasileira (Reinhardt et al., 2004; Morgado et al., 2004).

A cultivar Smooth Cayenne é a mais plantada no mundo, tanto em termos de área quanto em faixa de latitude, sendo considerada, atualmente, a principal cultivar de abacaxi, visto que possui muitas características favoráveis. O fruto tem aparência atraente, formato ligeiramente cilíndrico, apresentando casca de cor amarelo-alaranjada quando maduro, polpa amarela e rica em açúcares (13 a $19{ }^{\circ}$ Brix), com acidez maior que as demais cultivares; essas características a tornam adequada para a industrialização e a exportação como fruta fresca. Os frutos da cultivar Pérola apresentam forma cônica, casca amarelada (quando maduro), polpa branca e suculenta, com sólidos solúveis totais de 14 a $16{ }^{\circ}$ Brix, pouca acidez, sendo considerado o mais agradável ao paladar do brasileiro. O fruto, apesar da sua importância econômica para o Brasil, tem sido pouco utilizado, seja para a exportação in natura ou para a industrialização sob forma de rodelas $(\mathrm{Cu}-$ nha \& Cabral, 1999), razão pela qual se objetivou analisar a cinética da desidratação osmótica de frutos de duas cultivares de abacaxi, Pérola e Smooth Cayenne, em xarope de açúcar líquido invertido sem diluição.

\section{MATERIAL E MÉTODOS}

O experimento foi realizado no Laboratório de Engenharia Agrícola - LEAG, Centro de Ciências e Tecnologias Agropecuárias - CCTA, Universidade Estadual do Norte Fluminense Darcy Ribeiro - UENF, no município de Campos dos Goytacazes, RJ. Foram utilizados, no total, 16 frutos de abacaxizeiro (Ananas comosus (L.) Merrill), metade da cultivar Smooth Cayenne e metade da cultivar Pérola, fornecidos por produtores das regiões norte e noroeste do estado do Rio de Janeiro. Após recepção no laboratório, procedeu-se à seleção dos frutos a fim de homogeneizar o lote, de acordo com atributos de qualidade, como cor da casca, grau de maturação e ausência de injúrias ou doenças; depois de selecionados, os frutos foram armazenados em câmara do tipo B.O.D., a $8{ }^{\circ} \mathrm{C}$, com o objetivo de manter a sua qualidade, sendo retirados apenas para a realização dos experimentos.

No início de cada teste experimental foram retirados quatro frutos de uma mesma cultivar do ambiente de armazenamento, para determinação de algumas de suas propriedades, com o objetivo de se ter sua caracterização inicial; depois de removidas as coroas, os abacaxis foram lavados em água 
corrente e imersos em solução de detergente comercial neutro a $1 \%$ por $15 \mathrm{~min}$, para higienização e, finalmente, submergidos em água clorada (8 a 10 ppm de cloro ativo) durante 10 min, para sanitização, procedimento que foi seguido de enxágüe com água destilada.

Depois de descascados com faca de aço inoxidável, foram retiradas amostras dos frutos para determinação do teor de sólidos solúveis totais, $\mathrm{pH}$ e teor de água; as amostras foram homogeneizadas com microtriturador de aço inox, com cabeçote do tipo dentado com hélice (Tecnal, modelo Turratec TE 102) e pesadas em balança analítica (Sartorius, modelo BL 210S). O teor de sólidos solúveis totais (SST), em ${ }^{\circ}$ Brix, foi determinado colocando-se uma alíquota da amostra triturada sobre o prisma de um refratômetro portátil Atago, modelo HSR 500, procendendo-se à leitura do índice refratométrico indicado pelo aparelho. Para determinação do $\mathrm{pH}$, cerca de $3 \mathrm{~g}$ da amostra triturada foram diluídos em $20 \mathrm{~mL}$ de água destilada e o pH da suspensão foi determinado diretamente em potenciômetro Digimed, modelo DM 20. O teor de água foi definido por método gravimétrico, em estufa a vácuo, a $70^{\circ} \mathrm{C}$, durante $24 \mathrm{~h}$.

Os frutos foram então cortados manualmente, no formato de coroa circular com $10 \mathrm{~mm}$ de espessura; as dimensões típicas da coroa circular (Figura 1) são: DE (diâmetro externo), DI (diâmetro interno), R (raio externo), $\mathrm{r}$ (raio interno), $\mathrm{p}$ [raio médio $=(\mathrm{R}+\mathrm{r}) / 2$ ] e L (largura $=\mathrm{R}-\mathrm{r})$.

Logo em seguida e a fim de evitar o escurecimento enzimático, as amostras foram submetidas ao branqueamento, processo no qual elas foram expostas ao vapor d'água por $1 \mathrm{~min}$, sendo transferidas imediatamente para sacos

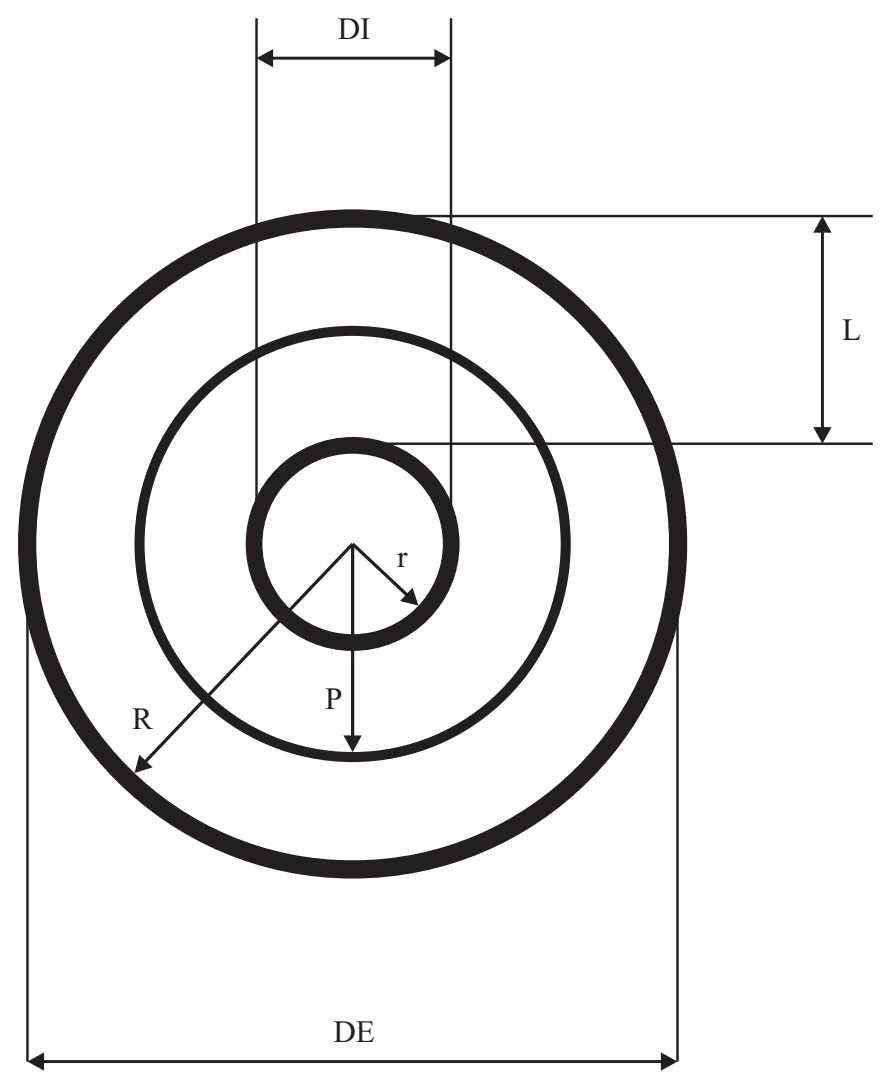

Figura 1. Representação geométrica de uma coroa circular plásticos e resfriadas em banho de gelo, durante $1 \mathrm{~min}$, evitando, desta forma, o contato das fatias com o banho de gelo, o qual poderia alterar o teor de água. Para geração de vapor utilizou-se um béquer de $1000 \mathrm{~mL}$ contendo cerca de $400 \mathrm{~mL}$ de água destilada, aquecida em chapa aquecedora, sobre o qual foi colocada uma tela metálica para sustentação das amostras; imediatamente depois do resfriamento as amostras foram imersas, pelo tempo de $5 \mathrm{~min}$, em solução de ácido ascórbico a 1\%, visando evitar o escurecimento não enzimático, conforme procedimentos sugeridos por Giangiacomo et al. (1987).

Realizou-se o processo de desidratação osmótica com o emprego de três agitadores de bancada, um da marca B. Braun Biotech International, modelo Certomat U/Certomat HK, e os outros dois fabricados pela Nova Ética, modelo 430 RDB. Todos os agitadores continham câmaras incubadoras para permitir o controle da temperatura durante a desidratação, empregando-se três béqueres de $1000 \mathrm{~mL}$ em cada agitador; depois da imersão em ácido ascórbico, as amostras foram colocadas nos béqueres em que, em cada um dos tratamentos, continha xarope de açúcar invertido sem diluição, empregando-se sempre a relação fruta:xarope de 1:10 (em massa); antes do início da desidratação a parte superior dos béqueres foi coberta com filme plástico para evitar a ocorrência de respingos ou derramamento da solução osmótica, o que alteraria a relação fruta/xarope; finalmente, depois dos pré-tratamentos e procedimentos já citados, teve início a coleta dos dados utilizados para descrição do processo de desidratação osmótica (redução de massa, perda de água e ganho de sólidos).

O tipo de agente osmótico empregado foi o xarope não diluído de açúcar invertido, com taxa de inversão maior que $90 \%$, com nome comercial Gludex 216 e fornecido pela Dulcini Alimentos, SP. Neste experimento se avaliaram dois níveis de temperatura de desidratação, 40 e $50^{\circ} \mathrm{C}$, e dois níveis de agitação da solução: zero e $60 \mathrm{~min}^{-1}$. Para a situação estática, a desidratação foi realizada em estufa com circulação forçada de ar; na condição dinâmica, fez-se o procedimento em incubadora-agitadora, como descrito antes. Em ambos os casos, as amostras permaneceram imersas na solução hipertônica durante $2 \mathrm{~h}$ e se avaliaram as variáveis descritas a seguir.

As determinações da redução de massa ( $\mu$ ), perda de água $(\omega)$ e ganho de sólidos ( $\delta$ ), foram realizadas em três repetições para cada tratamento, empregando-se apenas uma fatia de abacaxi por béquer; os valores de $\mu$, $\omega$ e $\delta$ foram medidos nos intervalos de 0, 15, 45, 75, 105 e 120 min. Depois de retiradas das soluções, as amostras foram enxaguadas em água destilada por cerca de $5 \mathrm{~s}$ com a finalidade de se retirar o excesso de soluto retido na superfície do produto, sendo posteriormente secadas em papel toalha para retirada do excesso de água superficial. A redução de massa $(\mu)$, a perda de água $(\omega)$ e o ganho de sólidos $(\delta)$, foram expressos em g $100 \mathrm{~g}^{-1}$ de massa inicial e calculados de acordo com as seguintes equações recomendadas por Silveira et al. (1996):

$$
\mu=\left(\frac{m_{i}-m_{i}}{m_{i}}\right) 100
$$




$$
\begin{aligned}
& \omega=\left(\frac{m_{i} X_{\text {ai }}-m_{t} X_{a t}}{m_{i}}\right) 100 \\
& \delta=\left(\frac{m_{t} X_{s t}-m_{i} X_{s i}}{m_{i}}\right) 100
\end{aligned}
$$

em que $m_{i}$ e $m_{t}$ representam a massa inicial e no tempo $t$, respectivamente; $X_{\mathrm{ai}}$ e $\mathrm{X}_{\mathrm{at}}$ (adimensionais) exprimem as frações de água na amostra, em massa, no início do experimento e no tempo t; e $\mathrm{X}_{\mathrm{si}}$ e $\mathrm{X}_{\mathrm{st}}$ expressam as frações de sólidos totais na amostra, em massa, no começo do experimento e no tempo t, respectivamente.

Os teores de SST, em ${ }^{\circ}$ Brix, tanto da solução quanto das fatias submetidas a desidratação osmótica, foram medidos em duas amostras separadas especialmente para este fim, em cada tratamento. Além da determinação para a condição inicial (tempo zero), retirou-se um pedaço de cada uma dessas amostras durante a desidratação e em seguida se mediu o teor de SST em duplicata; referidas amostras foram retiradas das soluções de desidratação nos intervalos de 30, 60, 90 e $120 \mathrm{~min}$; nesses mesmos intervalos se mediram os teores de SST das soluções osmóticas, também em duplicata, a fim de se verificar se sua concentração estava sendo mantida durante a desidratação osmótica; a manutenção do teor de SST durante o processo de desidratação osmótica é um indicativo da escolha correta para a relação fruta/xarope.

As amostras que foram utilizadas para estimar as características relativas à cinética da desidratação, também o foram para estimar os valores da redução de volume em função do tempo de desidratação osmótica. Quando as amostras eram retiradas da solução para monitorar os valores de $\delta$, $\mu$ e $\omega$ mediam-se, também, as seguintes dimensões da coroa circular (Figura 1): diâmetros externo (DE) e interno (DI) e altura ou espessura da fatia (h), em que o diâmetro externo foi medido em três posições diferentes; o diâmetro interno, assim como a altura da coroa, foram medidos em duas posições diferentes.

$\mathrm{O}$ experimento foi realizado em delineamento inteiramente casualizado, segundo esquema fatorial 2 × 2 × 2 × 6 (dois níveis de temperatura, dois níveis de grau de agitação, duas cultivares e seis intervalos de coleta de dados), para a redução de volume e as variáveis $\mu, \omega$ e $\delta$, com três repetições para cada tratamento; os dados foram interpretados por meio de análise de variância, enquanto as médias dos tratamentos foram comparadas aplicando-se o teste de Tukey e se adotando o nível de 5\% de probabilidade. Realizou-se a avaliação estatística dos resultados através do Aplicativo Computacional em Estatística Aplicada à Genética - Programa GENES, descrito por Cruz (1997).

\section{RESULTADOS E DISCUSSÃO}

\section{Caracterização inicial dos frutos}

Os valores de algumas das propriedades empregadas para caracterizar os frutos utilizados neste experimento, se encontram na Tabela 1 . Os valores relatados na literatura para algumas dessas propriedades apresentam intervalos significativos de variação que podem ser atribuídos a diversos fa- tores além da cultivar, como tipo de solo, clima, lâmina de irrigação, adubação, grau de amadurecimento dos frutos, dentre outros. Desta forma, para os frutos da cultivar Smooth Cayenne, os valores de massa relatados variaram entre 1,44 e $2,84 \mathrm{~kg}$, o pH, entre 3,20 e 4,20 e o teor de SST entre 9,48 e $15,49{ }^{\circ}$ Brix. Os intervalos de variação correspondentes para os dois frutos da cultivar Pérola, foram 0,95 a 1,66 kg, 3,87 a 4,02 e 9,69 a 16,00 ${ }^{\circ}$ Brix (Barreiro Neto et al., 2000; Teixeira et al., 2002; Bonnas et al., 2003; Reinhardt et al., 2004; Spironello et al., 2004; Granada et al., 2004; Souza et al., 2007). Segundo estudo realizado no ITAL (1987), o teor de água inicial dos frutos da cultivar Smooth Cayenne varia de 79,9 a $86,2 \%$ b.u. e o da cultivar Pérola de 80,0 a $86,0 \%$ b.u.; portanto, para a cultivar Smooth Cayenne se utilizaram, no presente trabalho, frutos mais ácidos e com teor de água inicial maior que os valores mencionados na literatura; para os frutos da cultivar Pérola se empregaram frutos ligeiramente mais pesados, mais ácidos, com menor teor de SST e maior teor de água inicial que aqueles relatados na literatura.

Tabela 1. Caracterização inicial dos frutos de abacaxi das cultivares Smooth Cayenne e Pérola utilizados no experimento

\begin{tabular}{lcr}
\hline \multirow{2}{*}{ Propriedade dos frutos } & \multicolumn{2}{c}{ Cultivar } \\
\cline { 2 - 3 } & Smooth Cayenne & Pérola \\
Massa (kg) & 2,25 & 1,69 \\
pH & 2,90 & 3,00 \\
Teor de água inicial (\% b.u.) & 91,90 & 93,00 \\
Teor de SST ('Brix) & 12,33 & 9,23 \\
\hline
\end{tabular}

\section{Teor de sólidos solúveis totais (SST) das soluções de desidratação osmótica}

A análise de variância evidenciou que o fator tempo de desidratação e sua interação com a temperatura da solução osmótica, foram as únicas fontes de variação que mostraram influência significativa pelo teste $\mathrm{F}(\mathrm{P}<0,01)$, sobre o teor de SST das soluções utilizadas, razão por que se procedeu ao teste de comparação das médias e os valores médios do teor de SST ( ${ }^{\circ}$ Brix) durante a desidratação osmótica, em todos os tratamentos estudados sob agitação da solução, são mostrados na Tabela 2.

Tabela 2. Valores médios do teor de sólidos solúveis totais ( ${ }^{\circ}$ Brix) da solução de desidratação, ao longo de 120 min de imersão-impregnação, para dois níveis de temperatura, 40 e $50{ }^{\circ} \mathrm{C}$, para imersão de coroas circulares de abacaxi das cultivares Pérola e 5 mooth Cayenne em xarope de açúcar invertido sem diluição, em agitação de $60 \mathrm{~min}^{-1}$

\begin{tabular}{lccccc}
\hline & \multicolumn{5}{c}{ Teor de sólidos solúveis totais da solução ('Brix) } \\
\cline { 2 - 6 } Tratamento & $\mathbf{5}$ Tempo (min) \\
\cline { 2 - 6 } & $\mathbf{0}$ & $\mathbf{3 0}$ & $\mathbf{6 0}$ & $\mathbf{9 0}$ & $\mathbf{1 2 0}$ \\
Temperatura $40{ }^{\circ} \mathrm{C}$ & & & & & \\
Pérola & $70,15 \mathrm{Aa}$ & $65,45 \mathrm{Aab}$ & $63,30 \mathrm{Ab}$ & $61,75 \mathrm{Ab}$ & $64,00 \mathrm{Aab}$ \\
Smooth Cayenne & $70,05 \mathrm{Aa}$ & $62,95 \mathrm{ABb}$ & $59,70 \mathrm{Ab}$ & $61,35 \mathrm{Ab}$ & $64,80 \mathrm{Aab}$ \\
\hline Temperatura $50{ }^{\circ} \mathrm{C}$ & \multicolumn{5}{c}{} \\
Pérola & $70,20 \mathrm{Aa}$ & $61,50 \mathrm{ABb}$ & $61,95 \mathrm{Ab}$ & $62,75 \mathrm{Ab}$ & $63,95 \mathrm{Aab}$ \\
Smooth Cayenne & $70,00 \mathrm{Aa}$ & $56,80 \mathrm{Bc}$ & $60,35 \mathrm{Abc}$ & $63,55 \mathrm{Ab}$ & $65,30 \mathrm{Aab}$ \\
\hline
\end{tabular}

Médias seguidas da mesma letra maiúscula na coluna e da mesma letra minúscula na linha, não diferiram significativamente, a $5 \%$ de probabilidade, pelo Teste de Tukey 
Os resultados indicados nesta Tabela, evidenciam que foram significativas as variações no valor do teor de SST, para as duas temperaturas e ambas as cultivares, ao longo do processo de imersão-impregnação; no entanto, quando se comparam os valores iniciais com aqueles obtidos aos 120 min, não se verifica diferença estatisticamente significativa entre eles; a redução que se observa no valor do teor de SST nos primeiros 30 min do processo e sua manutenção por determinado período de desidratação se devem, provavelmente, à rápida perda de água das fatias de abacaxi quando imersas em solução hipertônica com elevado potencial osmótico, como é o caso do xarope de açúcar invertido sem diluição.

Os valores mostrados na Tabela 2 demonstram, também, que a relação fruta/xarope utilizada, 1:10, foi suficiente para manutenção da concentração da solução durante as $2 \mathrm{~h}$ de desidratação osmótica; este resultado corrobora com a afirmação de vários autores, que asseguram ser oportuna a utilização de valores elevados para a relação fruta:xarope, tais como 1:10 (Rastogi \& Raghavarao, 2004), 1:20 (Corzo \& Gomez, 2004), 1:60 (Martínez et al., 2007), para manutenção da concentração inicial da solução. Verifica-se, além desse resultado, que para cada intervalo de tempo os valores do teor de SST foram estatisticamente os mesmos, independente da temperatura de desidratação e da cultivar do fruto, à exceção do valor medido aos 30 min de desidratação, para frutos da cultivar Smooth Cayenne desidratados a $50{ }^{\circ} \mathrm{C}$. A variação percentual no teor de SST da solução quando se comparam os valores iniciais e finais, esteve entre 6,71 e 8,90\%. Lenart (1996) afirma que, em geral e para condições semelhantes, ocorrem reduções de cerca de 5\% no teor de SST das soluções durante a desidratação osmótica. Giangiacomo et al. (1987), estudando os teores de diferentes tipos de açúcar (frutose, glicose, maltose e sacarose) em soluções hipertônicas ao longo de 6 h de desidratação osmótica de cerejas, pêssegos e damascos, empregando relação fruta:xarope de 1:5, não observaram variações significativas nos teores desses açúcares. Hough et al. (1993), desidratando fatias de maçã em solução de glicose a $55 \%$ e empregando relação fruta:xarope maior que 1:10, constataram variações inferiores a $5 \%$ no teor de SST, durante $5 \mathrm{~h}$ de desidratação.

Os resultados da Tabela 2 permitem constatar, também, que as taxas de redução no teor de SST das soluções a $50^{\circ} \mathrm{C}$, para as duas cultivares, foram mais acentuadas nos primeiros $30 \mathrm{~min}$ que aquelas verificadas a $40^{\circ} \mathrm{C}$; no entanto, a tendência de redução no teor de SST das soluções para desidratação a $40^{\circ} \mathrm{C}$, se prolonga até 60 min (Smooth Cayenne) e 90 min (Pérola); depois dessas reduções, os valores do teor de SST tendem a aumentar e se aproximam de um valor final médio de $64,51^{\circ}$ Brix; a perda de água no início da desidratação osmótica é rápida, atuando no sentido de diluir as soluções; posteriormente, com a redução nas taxas de impregnação de soluto e perda de água, há tendência de estabilização na concentração da solução hipertônica.

\section{Teor de sólidos solúveis totais das fatias de abacaxi durante a desidratação osmótica}

A análise de variância referente aos efeitos dos fatores tempo, cultivar e temperatura, e suas interações, sobre o teor de sólidos solúveis totais ( ${ }^{\circ}$ Brix) das amostras de abacaxi submetidas à desidratação osmótica em xarope de açúcar invertido sem diluição, indicou que houve efeito significativo pelo teste $\mathrm{F}(\mathrm{P}<0,01)$, apenas do fator tempo de desidratação; sendo assim, são apresentados, na Tabela 3, os valores médios do teor de SST ( ${ }^{\circ}$ Brix) das fatias de abacaxi obtidos durante a desidratação osmótica, para todos os tratamentos estudados sob agitação da solução.

Tabela 3. Valores médios do teor de sólidos solúveis totais ( ${ }^{\circ}$ Brix) de coroas circulares de abacaxi das cultivares Pérola e Smooth Cayenne ao longo de 120 min de desidratação osmótica, a 40 e $50{ }^{\circ} \mathrm{C}$, para imersão em xarope de açúcar invertido sem diluição, em agitação de $60 \mathrm{~min}^{-1}$

\begin{tabular}{lrrrrc}
\hline \multirow{2}{*}{ Tratamento } & \multicolumn{5}{c}{ Teor de sólidos solúveis totais das fatias de abacaxi ('Brix) } \\
\cline { 2 - 6 } & \multicolumn{5}{c}{ Tempo (min) } \\
\cline { 2 - 6 } & $\mathbf{0}$ & $\mathbf{3 0}$ & $\mathbf{6 0}$ & $\mathbf{9 0}$ & $\mathbf{1 2 0}$ \\
Temperatura $40^{\circ} \mathrm{C}$ & & & & & \\
Pérola & $8,80 \mathrm{Ab}$ & $28,97 \mathrm{Aa}$ & $32,35 \mathrm{Aa}$ & $36,65 \mathrm{Aa}$ & $37,10 \mathrm{Aa}$ \\
Smooth Cayenne & $12,60 \mathrm{Ab}$ & $30,40 \mathrm{Aa}$ & $38,55 \mathrm{Aa}$ & $38,80 \mathrm{Aa}$ & $37,45 \mathrm{Aa}$ \\
\hline Temperatura $50{ }^{\circ} \mathrm{C}$ & & & & & \\
Pérola & $8,70 \mathrm{Ab}$ & $25,65 \mathrm{Aa}$ & $33,70 \mathrm{Aa}$ & $38,70 \mathrm{Aa}$ & $37,60 \mathrm{Aa}$ \\
Smooth Cayenne & $10,87 \mathrm{Ad}$ & $26,90 \mathrm{Ac}$ & $30,10 \mathrm{Abc}$ & $48,15 \mathrm{Aa}$ & $43,95 \mathrm{Aab}$ \\
\hline
\end{tabular}

Médias seguidas da mesma letra maiúscula na coluna e da mesma letra minúscula na linha, não diferiram significativamente, a $5 \%$ de probabilidade, pelo Teste de Tukey

Observa-se que o teor de SST das fatias durante a desidratação osmótica se alterou significativamente entre o início e o final do processo para todos os tratamentos avaliados. A mudança abrupta no teor de SST das fatias ocorreu nos primeiros 30 min da desidratação e o valor se manteve praticamente inalterado a partir de então, comportamento que evidencia que a penetração de solutos na matriz do produto foi rápida e, devido à alta concentração da solução, provavelmente os sítios disponíveis para impregnação foram praticamente ocluídos nas fases iniciais do processo não permitindo, desta maneira, alterações posteriores no teor de SST; observa-se, então, que a concentração final de sólidos solúveis nas frutas foi estatisticamente igual para todos os tratamentos, ou seja, não houve efeito da temperatura de desidratação nem da cultivar da fruta cujos resultados diferem daqueles verificados por Dionello et al. (2007) que, ao compararem a desidratação osmótica de fatias de abacaxi em soluções de sacarose $\left(0,40,0,44\right.$ e $\left.0,47 \mathrm{~g} \mathrm{~mL}^{-1}\right)$ e açúcar invertido, a 40 e $50^{\circ} \mathrm{C}$, observaram maior nível de impregnação a medida em que a temperatura da solução osmótica aumentava.

Aumentos da ordem de 3 a 4 vezes no teor de sólidos solúveis das amostras de abacaxi foram observados nesse experimento, ao final de $2 \mathrm{~h}$ de desidratação. Sampaio et al. (2001) observaram, estudando a desidratação osmótica de abacaxi em solução de sacarose ( $70^{\circ}$ Brix), aumento da ordem de 3 vezes no teor de SST nas primeiras $2 \mathrm{~h}$ a $40^{\circ} \mathrm{C}$. Fito (1994) notou que, durante a desidratação osmótica de fatias de maçã a $50{ }^{\circ} \mathrm{C}$ em solução de sacarose a $65 \%$, o teor de SST aumentou de 10 para $48^{\circ} \mathrm{Brix}$, correspondendo a um incremento de aproximadamente 5 vezes no teor de SST. 


\section{Redução de volume das coroas circulares de abacaxi durante a desidratação osmótica}

A análise de variância referente aos efeitos dos diversos fatores avaliados neste trabalho, e suas interações sobre a redução do volume das coroas circulares de abacaxi, mostrou efeito significativo pelo teste $\mathrm{F}(\mathrm{P}<0,01)$, apenas do tempo de desidratação e da cultivar do fruto. A redução de volume das amostras que ocorre durante o processamento osmótico, de acordo com Viberg et al. (1998), deve-se, principalmente à perda de água pelo produto. $\mathrm{O}$ grau de encolhimento é um dos fatores determinantes da aparência final do produto desidratado e pode ser utilizado para simular, com maior grau de precisão, a cinética da desidratação osmótica. Como ocorreu efeito significativo dos dois fatores mencionados sobre a variável avaliada, procedeu-se ao teste de comparação das médias. A Tabela 4 mostra os valores normalizados de volume das fatias de abaca$\mathrm{xi}$, em todos os tratamentos estudados; ao volume inicial, ou seja, no tempo zero, foi arbitrado o valor 100; portanto, as reduções de volume podem ser avaliadas em termos percentuais; esses resultados mostram que a única variação significativa de volume se deu para o tratamento correspondente às amostras de abacaxi da cultivar Pérola, desidratadas a $50{ }^{\circ} \mathrm{C}$, sem agitação; portanto, em termos gerais se pode considerar que não foram significativas as alterações de volume das coroas circulares de abacaxi ao longo de $2 \mathrm{~h}$ de desidratação em xarope não diluído de açúcar invertido, independente da cultivar do fruto, da temperatura e do grau de agitação do xarope.

Em geral, há grande variabilidade nos parâmetros que caracterizam a desidratação osmótica de frutas e legumes e uma das possíveis explicações para este fato é a ocorrência de diferenças inerentes às características iniciais do produto, como firmeza da polpa (Giangiacomo et al., 1987), teores de sólidos solúveis e insolúveis iniciais (Lenart \& Flink, 1984), dimensões dos espaços intercelulares e relação entre as diferentes frações pécticas (Forni et al., 1986); esta variabilidade tem sido observada quando a desidratação osmótica é realizada em amostras de diferentes cultivares de um mesmo produto, em condições idênticas de desidratação. Torreggiani (1993), por exemplo, observou tal comportamento na desidratação osmótica de diferentes cultivares de damasco. Spiazzi \& Mascheroni (1997), estudando a redução de volume durante 120 min de desidratação osmótica de fatias de maçã em polietilenoglicol (PEG), obtiveram reduções de 45 a 56\% no volume das amostras. No presente trabalho, a maior redução de volume foi de cerca de 35\% (Pérola, $50{ }^{\circ} \mathrm{C}, 2 \mathrm{~h}$, sem agitação).

\section{Redução de massa $(\mu)$}

A análise de variância relativa aos efeitos dos fatores estudados e suas interações sobre a redução de massa $(\mu)$ das coroas circulares de abacaxi, mostrou efeito significativo pelo teste $\mathrm{F}(\mathrm{P}<0,01)$, do tempo, temperatura, grau de agitação e cultivar, assim como das interações tempo $\mathrm{x}$ cultivar, temperatura $\mathrm{x}$ grau de agitação e cultivar $\mathrm{x}$ grau de agitação. A Tabela 5 mostra os valores da redução de massa em g $100 \mathrm{~g}^{-1}$ de amostra inicial. Verifica-se que houve diferença significativa entre os valores de redução de massa das coroas circulares de abacaxi das cultivares Pérola e Smooth Cayenne, tanto a 40 quanto a $50{ }^{\circ} \mathrm{C}$, para desidratação osmótica com e sem agitação. As amostras da cultivar Pérola apresentaram maiores reduções de massa que as amostras da cultivar Smooth Cayenne. Mavroudis et al. (1998) afirmam haver variabilidade muito elevada nos parâmetros da cinética da desidratação osmótica em função das cultivares de uma mesma fruta, o que leva a diferentes reduções de massa em diferentes cultivares.

Constata-se, para a desidratação a $40{ }^{\circ} \mathrm{C}$ na Tabela 5 , que não houve efeito significativo do grau de agitação sobre a redução de massa de amostras de abacaxi de uma mesma cultivar. No caso da desidratação a $50{ }^{\circ} \mathrm{C}$, apenas para as amostras da cultivar Pérola não se observaram diferenças significativas no valor de $\mu$, com e sem agitação da solução osmótica; entretanto, as amostras da cultivar Smooth Cayenne desidratadas sem agitação, apresentaram redução de massa maior (16,44 g $100 \mathrm{~g}^{-1}$ de amostra inicial) e estatisticamente diferente das amostras que foram agitadas $\left(10,35 \mathrm{~g} 100 \mathrm{~g}^{-1}\right.$

Tabela 4. Valores médios de volume normalizado de coroas circulares de abacaxi das cultivares Pérola e Smooth Cayenne, em relação ao volume inicial (considerado como 100), ao longo de 120 min de desidratação, para dois níveis de temperatura, 40 e $50{ }^{\circ} \mathrm{C}$, para imersão em xarope de açúcar invertido sem diluição, em dois níveis de agitação, zero e $60 \mathrm{~min}^{-1}$

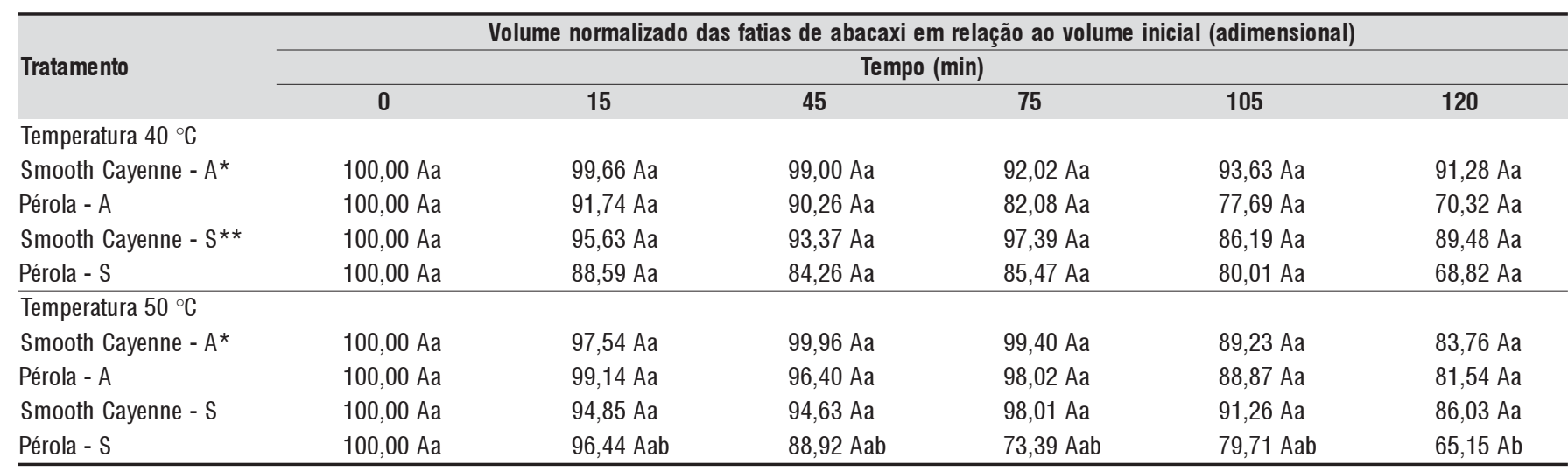

Médias seguidas da mesma letra maiúscula na coluna e da mesma letra minúscula na linha, não diferiram significativamente, a $5 \%$ de probabilidade, pelo Teste de Tukey. $A^{*}$ : Amostras desidratadas com agitação a $60 \mathrm{~min}^{-1} ; \mathrm{S}^{* *}$ Amostras desidratadas sem agitação 
Tabela 5. Valores médios de redução de massa ( $\mu$ ) de coroas circulares de abacaxi das cultivares Pérola e Smooth Cayenne, ao longo de 120 min de desidratação osmótica, para dois níveis de temperatura, 40 e $50{ }^{\circ} \mathrm{C}$, para imersão em xarope de açúcar invertido sem diluição, em dois níveis de agitação, zero e 60 min $^{-1}$

\begin{tabular}{|c|c|c|c|c|c|c|}
\hline \multirow{3}{*}{ Tratamento } & \multicolumn{6}{|c|}{ Redução de massa (g $100 \mathrm{~g}^{-1}$ de amostra inicial) } \\
\hline & \multicolumn{6}{|c|}{ Tempo (min) } \\
\hline & 0 & 15 & 45 & 75 & 105 & 120 \\
\hline \multicolumn{7}{|l|}{ Temperatura $40^{\circ} \mathrm{C}$} \\
\hline Smooth Cayenne $\left(A^{*}\right)$ & $0,00 \mathrm{Ab}$ & $3,96 \mathrm{ABab}$ & 6,29 Ba & 7,67 Ba & $8,73 \mathrm{Ca}$ & 9,45 Da \\
\hline Pérola $\left(S^{* *}\right)$ & $0,00 \mathrm{Ad}$ & $7,40 \mathrm{ABc}$ & $10,88 \mathrm{ABbc}$ & 14,49 Aab & $17,17 \mathrm{Aa}$ & $18,52 \mathrm{ABa}$ \\
\hline Pérola $\left(A^{*}\right)$ & $0,00 \mathrm{Ad}$ & $3,98 \mathrm{ABcd}$ & $9,61 \mathrm{ABc}$ & $15,99 \mathrm{Ab}$ & 19,64 Aab & $20,87 \mathrm{ABa}$ \\
\hline Smooth Cayenne $\left(A^{*}\right)$ & $0,00 \mathrm{Ac}$ & $3,35 \mathrm{Bbc}$ & $5,29 \mathrm{Babc}$ & 6,97 Bab & $8,73 \mathrm{Cab}$ & $10,35 \mathrm{Da}$ \\
\hline Pérola $\left(S^{* *}\right)$ & $0,00 \mathrm{Ad}$ & $8,66 \mathrm{ABc}$ & $12,61 \mathrm{Ac}$ & $16,23 \mathrm{Abc}$ & $19,14 \mathrm{Aab}$ & $22,73 \mathrm{Aa}$ \\
\hline Smooth Cayenne $\left(S^{\star \star}\right)$ & $0,00 \mathrm{Ac}$ & $7,17 \mathrm{ABb}$ & $11,00 \mathrm{ABab}$ & $12,50 \mathrm{ABab}$ & $15,21 \mathrm{ABa}$ & $16,44 \mathrm{BCa}$ \\
\hline
\end{tabular}

Médias seguidas da mesma letra maiúscula na coluna e da mesma letra minúscula na linha, não diferiram significativamente, a $5 \%$ de probabilidade, pelo Teste de Tukey.

$A^{*}$ : Amostras desidratadas com agitação de $60 \mathrm{~min}^{-1} ; \mathrm{S}^{* *}$ : Amostras desidratadas sem agitação

de amostra inicial). Esta variabilidade pode estar associada a características intrínsecas da cultivar, que se manifestam quando a fruta é submetida a temperaturas mais elevadas de desidratação. A redução de massa das fatias ocorreu até os 105 min de desidratação e, a partir de então, os valores não diferiram estatisticamente nem existiu efeito significativo da temperatura para nenhuma das cultivares estudadas; entretanto, em valores absolutos as fatias que foram desidratadas a $50{ }^{\circ} \mathrm{C}$ apresentaram maior redução de massa que aquelas desidratados em $40^{\circ} \mathrm{C}$. Resultados semelhantes foram relatados por Torreggiani (1993) e Raoult-Wack (1994).

\section{Perda de água $(\omega)$}

A análise de variância da perda de água $(\omega)$ das coroas circulares de abacaxi demonstrou que houve efeito significativo pelo teste $\mathrm{F}(\mathrm{P}<0,01)$, dos quatro fatores avaliados, assim como das interações tempo $\mathrm{x}$ cultivar, temperatura $\mathrm{x}$ cultivar, temperatura $\mathrm{x}$ grau de agitação e cultivar $\mathrm{x}$ grau de agitação. Observando-se diferenças significativas para o efeito dos fatores citados acima sobre os valores da variável perda de água $(\omega)$, procedeu-se ao teste de médias. A Tabela 6 mostra a perda de água que ocorre nas coroas circulares de abacaxi (g $100 \mathrm{~g}^{-1}$ de amostra inicial) em todos os tratamentos estudados; verifica-se, portanto, que a perda de água das fatias de abacaxi mostrou diferenças significativas, tanto ao longo do tempo de desidratação para cada tratamento como entre os tratamentos, para cada intervalo de tempo. Observa-se que os valores de $\omega$ aumentaram significativamente até os 105 min de desidratação enquanto se constatou, na desidratação a 40 e $50^{\circ} \mathrm{C}$, para os tratamentos realizados com amostras da cultivar Pérola, perda de água significativamente maior que aquelas observadas com amostras da cultivar Smooth Cayenne, para as mesmas condições experimentais. Torreggiani \& Bertolo (2001) relataram resultados similares em trabalho de desidratação osmótica empregando três cultivares de morango.

Não se observa, na desidratação a $40^{\circ} \mathrm{C}$, efeito significativo do grau de agitação da solução mas a $50{ }^{\circ} \mathrm{C}$ só existiu efeito da agitação para o tratamento com a cultivar Smooth Cayenne, que apresentou maior perda de água nas amostras

Tabela 6. Valores médios da perda de água ( $\omega)$ de coroas circulares de abacaxi das cultivares Pérola e Smooth Cayenne, ao longo de 120 min de desidratação osmótica, para dois níveis de temperatura, 40 e $50{ }^{\circ} \mathrm{C}$, para imersão em xarope de açúcar invertido sem diluição, em dois níveis de agitação, zero e $60 \mathrm{~min}^{-1}$

\begin{tabular}{|c|c|c|c|c|c|c|}
\hline \multirow{3}{*}{ Tratamento } & \multicolumn{6}{|c|}{ Perda de água (g $100 \mathrm{~g}^{-1}$ de amostra inicial) } \\
\hline & \multicolumn{6}{|c|}{ Tempo (min) } \\
\hline & 0 & 15 & 45 & 75 & 105 & 120 \\
\hline \multicolumn{7}{|l|}{ Temperatura: $40^{\circ} \mathrm{C}$} \\
\hline Smooth Cayenne $\left(A^{*}\right)$ & $0,00 \mathrm{Ac}$ & 6,96 BCbc & $10,90 \mathrm{Cab}$ & 13,67 Bab & 14,92 Cab & $16,08 \mathrm{Ca}$ \\
\hline Pérola $\left(S^{* *}\right)$ & $0,00 \mathrm{Ad}$ & $12,73 \mathrm{ABc}$ & $18,34 \mathrm{ABCbc}$ & $23,90 \mathrm{Aab}$ & $27,86 \mathrm{Aa}$ & $29,80 \mathrm{ABa}$ \\
\hline Pérola $\left(A^{*}\right)$ & $0,00 \mathrm{Ac}$ & $6,69 \mathrm{BCC}$ & $15,58 \mathrm{ABCb}$ & $24,84 \mathrm{Aa}$ & $29,82 \mathrm{Aa}$ & $31,43 \mathrm{ABa}$ \\
\hline Smooth Cayenne $\left(A^{\star}\right)$ & $0,00 \mathrm{Ac}$ & $5,87 \mathrm{Cbc}$ & 9,17 Cab & $11,97 \mathrm{Bab}$ & $14,83 \mathrm{Ca}$ & $17,41 \mathrm{Ca}$ \\
\hline Pérola $\left(\mathrm{S}^{* *}\right)$ & $0,00 \mathrm{Ae}$ & $14,89 \mathrm{Ad}$ & 21,19 Acd & $26,69 \mathrm{Abc}$ & 30,92 Aab & $35,90 \mathrm{Aa}$ \\
\hline Smooth Cayenne $\left(S^{* *}\right)$ & $0,00 \mathrm{Ac}$ & $12,29 \mathrm{ABb}$ & 18,44 ABCab & $20,78 \mathrm{ABab}$ & $24,88 \mathrm{ABa}$ & $26,69 \mathrm{Ba}$ \\
\hline
\end{tabular}

Médias seguidas da mesma letra maiúscula na coluna e da mesma letra minúscula na linha, não diferiram significativamente, a $5 \%$ de probabilidade, pelo Teste de Tukey. $\mathrm{A}^{*}$ : Amostras desidratadas com agitação de $60 \mathrm{~min}^{-1} ; \mathrm{S}^{* *}$ : Amostras desidratadas sem agitação 
desidratadas sem agitação (26,69 g $100 \mathrm{~g}^{-1}$ de amostra inicial) que para as que foram agitadas durante a desidratação osmótica (17,41 g $100 \mathrm{~g}^{-1}$ de amostra inicial). Lo Scalzo et al. (2001) também observaram diferenças significativas nos valores de perda de água em função da cultivar, durante a desidratação osmótica a $25^{\circ} \mathrm{C}$, por $6 \mathrm{~h}$, de fatias de melão em solução de sacarose a $60 \%$; já para a cultivar Mirado, a

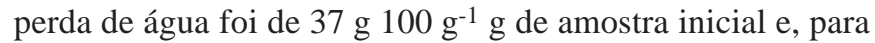

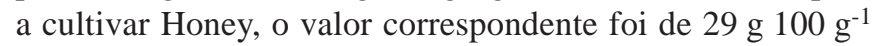
de amostra inicial. De acordo com Lo Scalzo et al. (2001), possíveis diferenças na estrutura do tecido da fruta poderiam resultar nos diferentes comportamentos observados entre as duas cultivares.

\section{Ganho de Sólidos ( $\delta$ )}

A análise de variância relativa aos efeitos dos fatores estudados e suas interações, sobre o ganho de sólidos $(\delta)$ pelas coroas circulares de abacaxi, mostrou que houve efeito significativo pelo teste $\mathrm{F}(\mathrm{P}<0,01)$, dos fatores tempo, cultivar e grau de agitação e das interações tempo x cultivar, temperatura x cultivar, temperatura x grau de agitação, cultivar x grau de agitação e da interação tripla tempo x temperatura x grau de agitação. De vez que se observaram efeitos significativos dos três fatores e várias de suas interações sobre os valores da variável ganho de sólidos $(\delta)$, procedeuse ao teste de médias. A Tabela 7 mostra o ganho de sólidos que ocorreu nas coroas circulares de abacaxi (g $100 \mathrm{~g}^{-1}$ de amostra inicial) em todos os tratamentos estudados.

Da mesma forma que para a redução de massa $(\mu)$ e perda de água $(\omega)$, o ganho de sólidos das amostras de abacaxi, para todos os tratamentos avaliados, variou estatisticamente ao longo do tempo de desidratação. A partir dos 75 min de desidratação não se constataram diferenças significativas entre qualquer um dos tratamentos. Autores como RaoultWack (1994) e Torreggiani (1993) observaram que a maior taxa de ganho de sólidos ocorre nos primeiros $30 \mathrm{~min}$ de desidratação. Moreira \& Sereno (2003), estudando a desidratação osmótica de maçãs, por 2 h, notaram que o maior nível de ganho de sólidos ocorreu na primeira hora de imer- são das amostras na solução hipertônica. Nota-se, na Tabela 7 que, em se mantendo as demais condições experimentais ao final de 120 min de desidratação, não se constataram diferenças significativas entre os valores de $\delta$ para as duas temperaturas estudadas.

Na desidratação osmótica a 40 e $50{ }^{\circ} \mathrm{C}$ ao final do processo, as amostras da cultivar Pérola apresentaram maior ganho de sólidos que aquelas da cultivar Smooth Cayenne, tanto com e sem agitação da solução. Alguns autores encontraram diferenças significativas no ganho de sólidos em função da cultivar, durante a desidratação osmótica de frutas, como Torreggiani \& Bertolo (2001) e Viberg et al. (1998) ao estudarem diferentes cultivares de morango, e Lo Scalzo et al. (2001) ao avaliarem duas cultivares de melão.

Ao final da desidratação a $40^{\circ} \mathrm{C}$ não se observaram diferenças significativas para o ganho de sólidos para amostras de ambas as cultivares, independente do fato da solução haver sido ou não agitada. Resultados semelhantes foram relatados por Moreira \& Sereno (2003) e Mavroudis et al. (1998); a $50{ }^{\circ} \mathrm{C}$ também não houve diferenças significativas no ganho de sólidos das amostras da cultivar Pérola, mas o ganho de sólidos nas amostras da cultivar Smooth Cayenne que foram agitadas, foi estatisticamente diferente daquele observado nas que não o foram, 7,07 e 10,25 g $100 \mathrm{~g}^{-1}$ de amostra inicial, respectivamente.

\section{CONCLUSÕES}

1. A relação fruta:xarope usada, 1:10, foi suficiente para manter inalterada a concentração da solução osmótica, ao longo de 2 h de desidratação.

2. Ocorreu aumento de cerca de três vezes no teor de sólidos solúveis totais das amostras de abacaxi cortadas no formato de coroa circular, não se observando diferenças em função da cultivar e da temperatura de desidratação.

3. A redução de massa, a perda de água e o ganho de sólidos, foram maiores para amostras da cultivar Pérola que para aquelas da cultivar Smooth Cayenne. A partir dos

Tabela 7. Valores médios do ganho de sólidos $(\delta)$ de coroas circulares de abacaxi das cultivares Pérola e Smooth Cayenne, ao longo de 120 min de desidratação osmótica, para dois níveis de temperatura, 40 e $50{ }^{\circ} \mathrm{C}$, para imersão em xarope de açúcar invertido sem diluição, em dois níveis de agitação, zero e $60 \mathrm{~min}^{-1}$

\begin{tabular}{|c|c|c|c|c|c|c|}
\hline \multirow{3}{*}{ Tratamento } & \multicolumn{6}{|c|}{ Ganho de sólidos (g $100 \mathrm{~g}^{-1}$ de amostra inicial) } \\
\hline & \multicolumn{6}{|c|}{ Tempo $(\min )$} \\
\hline & 0 & 15 & 45 & 75 & 105 & 120 \\
\hline \multicolumn{7}{|l|}{ Temperatura $40^{\circ} \mathrm{C}$} \\
\hline Smooth Cayenne $\left(A^{*}\right)$ & $0,00 \mathrm{Ac}$ & $2,99 \mathrm{BCb}$ & $4,61 \mathrm{BCab}$ & $5,71 \mathrm{BCab}$ & $6,18 \mathrm{Ba}$ & 6,63 Da \\
\hline Pérola $\left(S^{* \star}\right)$ & $0,00 \mathrm{Ad}$ & $5,33 \mathrm{ABCC}$ & $7,46 \mathrm{ABbc}$ & $9,41 \mathrm{Aab}$ & $10,69 \mathrm{Aa}$ & $11,28 \mathrm{ABa}$ \\
\hline Pérola $\left(A^{\star}\right)$ & $0,00 \mathrm{Ac}$ & $2,71 \mathrm{Cd}$ & $5,97 \mathrm{ABCb}$ & $8,85 \mathrm{Aa}$ & $10,18 \mathrm{Aa}$ & $10,56 \mathrm{ABCa}$ \\
\hline Smooth Cayenne $\left(A^{*}\right)$ & $0,00 \mathrm{Ac}$ & $2,52 \mathrm{Ccd}$ & $3,88 \mathrm{Cbc}$ & 4,99 Cabc & 6,10 Bab & 7,07 Da \\
\hline Pérola $\left(S^{* *}\right)$ & $0,00 \mathrm{Ae}$ & $6,23 \mathrm{Ac}$ & $8,59 \mathrm{Abc}$ & $10,46 \mathrm{Aab}$ & $11,78 \mathrm{Aa}$ & $13,17 \mathrm{Aa}$ \\
\hline Smooth Cayenne $\left(S^{* *}\right)$ & $0,00 \mathrm{Ac}$ & $5,12 \mathrm{ABCb}$ & $7,43 \mathrm{ABab}$ & $8,28 \mathrm{ABa}$ & $9,67 \mathrm{Aa}$ & $10,25 \mathrm{BCa}$ \\
\hline
\end{tabular}

Médias seguidas da mesma letra maiúscula na coluna e da mesma letra minúscula na linha, não diferiram significativamente, a 5\% de probabilidade pelo Teste de Tukey. $A^{*}$ : Amostras desidratadas com agitação de $60 \mathrm{~min}^{-1} ; \mathrm{S}^{* *}$ : Amostras desidratadas sem agitação 
105 min de desidratação osmótica não houve variações significativas para as três características estudadas.

\section{AGRADECIMENTOS}

Os autores agradecem o apoio técnico e financeiro das seguintes instituições: CNPq, Dulcini S.A., FAPERJ, FINEP e International Foundation for Science - IFS.

\section{LITERATURA CITADA}

Azuara, E.; Beristain, C.; Gutiérrez, G. F. Osmotic dehydration of apples by immersion in concentrated sucrose/maltodextrin solutions. Journal of Food Processing Preservation, v.26, n.4, p.295-306, 2002.

Barreiro Neto, M. B.; Lacerda, J. T.; Choairy, S. A.; Oliveira, E. F.; Carvalho, R. A.; Franco, C. F. O. Testes de novos híbridos de abacaxizeiro visando à agricultura familiar. 2000. http:// www.emepa.org.br/abacaxi_hibr.php. 15 Fev. 2008.

Bonnas, D. S.; Chitarra, A. B.; Prado, M. E. T.; Teixeira Júnior, D. Qualidade do abacaxi cv Smooth Cayenne minimamente processado. Revista Brasileira de Fruticultura, v.25, n.2, p.206-209, 2003.

Corzo, O.; Gomez, E. R. Optimization of osmotic dehydration of cantaloupe using desired function methodology. Journal of Food Engineering, v.64, n.2, p.213-219, 2004.

Cruz, C. D. Programa GENES - Aplicativo computacional em genética e estatística. 1.ed. Viçosa: UFV, 1997. 442p.

Cunha, G. A. P.; Cabral, J. R. S. Taxonomia, espécies, cultivares e morfologia. In: Cunha, G. A. P.; Cabral, J. R. S.; Souza, L. F. S. (ed.). O abacaxizeiro - Cultivo, agroindústria e economia. Brasília: EMBRAPA, 1999. cap.1, p.17-51.

Dionello, R. G.; Berbert, P. A.; Molina, M. A. B.; Viana, A. P.; Carlesso, V. O.; Queiroz, V. A. V. Desidratação por imersãoimpregnação de abacaxi em soluções de sacarose e em xarope de açúcar invertido. Ciência e Tecnologia de Alimentos, v.27, n.4, p.701-709, 2007.

DULCINI - Açúcares Líquidos Dulcini. Manual técnico. 1.ed. São Paulo: Dulcini S/A, 2000. 16p.

Ferrando, M.; Spiess, W. E .L. Cellular response of plant tissue during the osmotic treatment with sucrose, maltose, and trehalose solutions. Journal of Food Engineering, v.49, n.2-3, p.115-127, 2001.

Ferrari, C. C.; Rodrigues, L. K.; Tonon, R. V.; Hubinger, M. D. Cinética de transferência de massa de melão desidratado osmoticamente em soluções de sacarose e maltose. Ciência e Tecnologia de Alimentos, v.25, n.3, p.564-570, 2005.

Fito, P. Modelling of vacuum osmotic dehydration of food. Journal of Food Engineering, v.22, n.3/4, p.313-328, 1994.

Forni, E.; Torreggiani, D.; Battiston, P.; Polesello, A. Research into changes of pectic substances in apricots and peaches processed by osmotic dehydration. Carbohydrate Polymers, v.6, n.5, p.379-393, 1986.

Giangiacomo, R.; Torreggiani, D.; Abbo, E. Osmotic dehydration of fruit: Part 1. Sugar and extracting syrups. Journal of Food Processing and Preservation, v.11, n.3, p.183-195, 1987.
Granada, G. G; Zambiazi, R. C.; Mendonça, C. R. B. Abacaxi: Produção, mercado e subprodutos. Boletim do Centro de Pesquisa e Processamento de Alimentos, v.22, n.2, p.405-422, 2004.

Hansson, A.; Andersson, J.; Leufvén, A. The effects of sugars and pectin on flavour release from a soft drink-related model system. Food Chemistry, v.72, n.3, p.363-368, 2001.

Hough, G.; Chirife, J.; Marini, C. A simple model for osmotic dehydration of apples. Lebensmittel-Wissenschaft undTechnologie, v.26, n.2, p.151-156, 1993.

ITAL - Instituto de Tecnologia de Alimentos. Abacaxi: Cultura, matéria-prima, processamento e aspectos econômicos. 2.ed. Campinas: ITAL, 1987. 285p.

Lenart, A. Osmo-convective drying of fruits and vegetables: Technology and application. Drying Technology, v.14, n.2, p.391-413, 1996.

Lenart, A.; Flink, J. M. Osmotic concentration of potatoes II: Spatial distribution of the osmotic effect. International Journal of Food Science \& Technology, v.19, n.1, p.65-89, 1984.

Lo Scalzo, R.; Papadimitriu, C.; Bertolo, G.; Maestrelli, A. Influence of cultivar and osmotic dehydration time on aroma profiles of muskmelon (Cucumis melo, cv. reticulatus Naud.) spheres. Journal of Food Enginnering, v.49, n.2-3, p.261-264, 2001.

Martínez, V. Y.; Nieto, A. B.; Castro, M. A.; Salvatori, D.; Alzamora, S. M. Viscoelastic characteristics of Granny Smith apple during glucose osmotic dehydration. Journal of Food Engineering, v.83, n.3, p.394-403, 2007.

Mavroudis, N. E.; Gekas, V.; Sjöholm, I. Osmotic dehydration of apples - Effects of agitation and raw material characteristics. Journal of Food Engineering, v.35, n.2, p.191-209, 1998.

Moreira, R.; Sereno, A. M. Evaluation of mass transfer coefficients and volumetric shrinkage during dehydration of apple using sucrose solutions in static and non-static conditions. Journal of Food Engineering, v.57, n.1, p.25-31, 2003.

Morgado, I. F.; Aquino, C. N. P.; Terra, D. C. T. Aspectos econômicos da cultura do abacaxi: Sazonalidade de preços no Estado do Rio de Janeiro. Revista Brasileira de Fruticultura, v.26, n.1, p.44-47, 2004.

Queiroz, V. A. V. Qualidade de goiaba (Psidium guajava L.) submetida aos processos de desidratação por imersão-impregnação e secagem por convecção. Campos dos Goytacazes: UENF, 2006. 123p. Tese Doutorado

Queiroz, V. A. V.; Berbert, P. A.; Molina, M. A. B.; Gravina, G. A.; Queiroz, L. R.; Deliza, R. Desidratação por imersão-impregnação e secagem por convecção de goiaba. Pesquisa Agropecuária Brasileira, v.2, n.10, p.1479-1486, 2007.

Raoult-Wack, A. L. Recent advances in the osmotic dehydration of foods. Trends in Food Science and Technology, v.5, n.8, p.255-260, 1994.

Rastogi, N. K.; Raghavarao, K. S. M. S. Mass transfer during osmotic dehydration of pineapple: considering Fickian diffusion in cubical configuration. Lebensmittel-Wissenschaft und-Technologie, v.37, n.1, p.43-47, 2004.

Reinhardt, D. H.; Medina, V. M.; Caldas, R. C.; Cunha, G. A. P.; Estevam, R. F. H. Gradientes de qualidade em abacaxi 'Pérola' em função do tamanho e do estádio de maturação do fruto. Revista Brasileira de Fruticultura, v.26, n.3, p.544-546, 2004. 
Rizzolo, A.; Gerli, F.; Prinzivalli, C.; Buratti, S.; Torreggiani, D. Headspace volatile compounds during osmotic dehydration of strawberries (cv Camarosa): Influence of osmotic solution composition and processing time. Food Science and Technology, v.40, n.3, p.529-535, 2007.

Rodrigues, M. V. N.; Rodrigues, R. A. F.; Serra, G. E.; Andrietta, S. R.; Franco, T. T. Produção de xarope de açúcar invertido obtido por hidrólise heterogênea, através de planejamento experimental. Ciência e Tecnologia de Alimentos, v.20, n.1, p.103-109, 2000.

Rodrigues, S.; Fernandes, F. A. N. Image analysis of osmotically dehydrated fruits: melons dehydration in a ternary system. European Food Research and Technology, v.225, n.5-6, p.685-691, 2007.

Sampaio, S. M.; Magalhães, A. M.; Queiroz, M. R. Secagem e desidratação osmótica de abacaxi em secador de leito fixo. In: Congresso Brasileiro de Engenharia Agrícola, 30, 2001, Foz do Iguaçu. Resumos... Foz do Iguaçu: SBEA, 2001. CD-Rom

Silveira, E. T. F.; Rahman, M. S.; Buckle, K. A. Osmotic dehydration of pineapple: Kinetics and product quality. Food Research International, v.29, n.2-3, p.227-233, 1996.

Souza, C. B.; Silva, B. B.; Azevedo, P. V. Crescimento e rendimento do abacaxizeiro nas condições climáticas dos Tabuleiros Costeiros do Estado da Paraíba. Revista Brasileira de Engenharia Agrícola e Ambiental, v.11, n.2, p.134-141, 2007.
Spiazzi, E.; Mascheroni, R. Mass transfer model for osmotic dehydration of fruits and vegetables - I. Development of the simulation model. Journal of Food Engineering, v.34, n.4, p.387-410, 1997.

Spironello, A.; Quaggio, J. A.; Teixeira, L. A. J.; Furlani, P. R.; Sigrist, J. M. M. Pineapple yield and fruit quality effected by NPK fertilization in a tropical soil. Revista Brasileira de Fruticultura, v.26, n.1, p.155-159, 2004.

Teixeira, L. A. J.; Spironello, A.; Furlani, P. R. Sigrist, J. M. M. Parcelamento da adubação NPK em abacaxizeiro. Revista Brasileira de Fruticultura, v.24, n.1, p.219-224, 2002.

Torreggiani, D. Osmotic dehydration in fruit and vegetable processing. Food Research International, v.26, n.1, p.59-68, 1993.

Torreggiani, D.; Bertolo, G. High-quality fruit and vegetable products using combined processes. In: Fito, P.; Chiralt, A.; Barat, J. M.; Spiess, W. E. L.; Behsnilian, D. (ed.). Osmotic Dehydration \& Vacuum Impregnation - Aplication in Food Industries. Lancaster: Technomic Publishing Co., Inc., 2001. Chapter 1, p.3-9.

Viberg, U.; Freuler, S.; Gekas, V.; Sjöholm, I. Osmotic pretreatment of strawberries and shrinkage effects. Journal of Food Engineering, v.35, n.2, p.135-145, 1998. 